\title{
Corrigendum: The European dimension for the mouse genome mutagenesis program
}

The European Mouse Mutagenesis Consortium

Nat. Genet. 36, 925-927 (2004).

The authors Johan Auwerx and Pierre Chambon are both affiliated with the Mouse Clinical Institute (MCI), Illkirch, Strasbourg, France.

Erratum: Nonsense surveillance regulates expression of diverse classes of mammalian transcripts and mutes genomic noise

J T Mendell, N A Sharifi, J L Meyers, F Martinez-Murillo \& H C Dietz

Nat. Genet. 36, 1073-1078 (2004).

The second sentence of the first complete paragraph in the first column on page 1075 should read "Approximately 4,000 transcripts, representing $33 \%$ of the probe sets on the arrays, were expressed in HeLa cells and were assayed in these experiments."

Corrigendum: MicroRNA-responsive 'sensor' transgenes uncover Hox-like and other developmentally regulated patterns of vertebrate microRNA expression

J H Mansfield, B D Harfe, R Nissen, J Obenauer, J Srineel, A Chaudhuri, R Farzan-Kashani, M Zuker, A E Pasquinelli, G Ruvkun, P A Sharp, C J Tabin \& M T McManus

Nat. Genet. 36, 1079-1083 (2004).

Brian D. Harfe is affiliated only with the Department of Molecular Genetics and Microbiology at the University of Florida College of Medicine.

\section{Erratum: Global patterns of human mitochondrial DNA and Y-chromosome structure are not influenced by higher migration rates of females versus males}

J A Wilder, S B Kingan, Z Mobasher, M M Pilkington \& M F Hammer

Nat. Genet. 36, 1122-1125 (2004).

The first sentence of the introductory paragraph should begin "Global-scale patterns of human population structure may be influenced by a rate of migration...". The last sentence of the introductory paragraph should begin "Although patrilocality may be important at the local scale, patterns of genetic structure at the continental and global scales are not shaped by a higher rate of migration...." 